\title{
Use of Simulation in Teaching Nursing Leadership and Management Course An integrative review
}

Leodoro J. Labrague

\begin{abstract}
Nursing education is strategically positioned to prepare nursing students for management and leadership skills necessary for future professional nursing roles. This review appraised and synthesised the outcomes of using simulation in pre-licensure nursing management and leadership courses. This is an integrative review of original articles published between 2008 and 2018. In January 2019, PsychINFO, CINAHL, PubMed and SCOPUS were searched to identify relevant articles using the following terms: 'management', 'leadership', 'simulation, 'nursing', 'education' and 'student'. A total of 10 articles were included in the review. Four essential themes were identified from the content analysis: acquisition of skills or understanding of delegation, enhanced teamwork or collaboration capacities, improved decision-making and problem-solving skills and increased communication skills. Incorporation of simulation in the nursing management and leadership courses has the potential to enhance nursing students' skills regarding delegation, problem-solving capacities, decision-making and communication and teamwork.
\end{abstract}

Keywords: Simulation Training; Nursing; Leadership; Practice Management; Student; Education.

$\mathrm{N}$ URSING EDUCATION IS VITAL IN THE formation of student nurses' management and leadership competencies for future leadership roles. Several organisations, including academic institutions, healthcare agencies and accrediting entities, highlight the crucial need for student nurses to possess the leadership and management skills upon graduation. For example, the Institute of Medicine and the American Association of Colleges of Nursing suggest that all student nurses graduating from nursing school possess management and leadership competencies necessary in working and collaborating with multidisciplinary healthcare teams. ${ }^{1,2}$ In particular, the American Organization of Nurse Executives (AONE) developed the Nurse Managers Competencies Framework to guide nursing schools in the development of their undergraduate and graduate curricula to successfully educate nursing students with essential management and leadership skills required in the performance of nurse manager roles. ${ }^{3}$ These competencies include the following: resource management, management of patient care delivery, staff development, compliance with professional and regulatory standards, long-term and strategic planning, inter-professional management and leadership and collaboration with other units within the institution. ${ }^{3}$

In many nursing schools, students are provided opportunities to imbibe skills in leading and managing when they attend a leadership and management course in the terminal year of their undergraduate nursing programme. However, facilitating and teaching lead- ership and management skills among nursing students remains a significant challenge to nursing faculty due to several factors such as increasing nursing student applications for admission, nursing faculty shortage and limited clinical placements to facilitate and integrate leadership concepts in clinical practice. ${ }^{4-6}$ Unsurprisingly, many nurse managers and nurse executives perceive newly graduated nurses as not being sufficiently ready to perform leadership roles and responsibilities as well as lacking management skills when they start working as a professional nurse. ${ }^{7}$

Alternative teaching approaches using simulations are vital to adequately prepare students for their future leadership roles as nursing professionals. Simulation is identified as a viable and supplementary teaching modality to facilitate the translation of theoretical concepts in nursing into practice. ${ }^{8,9}$ The use of simulation is acknowledged as an indispensable aspect of the nurse education curriculum and has been widely used across all nursing courses. These include the following: Fundamentals of Nursing, Maternal and Child Health, Adult Health, Mental and Psychiatric Health, Community Health and Critical Care courses. ${ }^{10-15}$ In particular, simulation studies have identified medium- to high-fidelity simulations as potent teaching modalities to foster students' nursing competence, self-efficacy, critical thinking and reasoning, communication and interpersonal skills and clinical judgment. ${ }^{16-21}$

Numerous nursing education institutions have supported the integration of simulation-based activities 
into their respective pedagogies. The National Council of State Boards of Nursing endorses the use of simulation-based activities as an alternative to usual clinical experiences to provide relevant and essential clinical experiences for nursing students. ${ }^{22}$ The National League of Nursing supports the incorporation of simulation-based activities in nursing programmes to adequately prepare students for future nursing practice amidst the growing challenges in the field of healthcare.

Available evidence suggests that through simulation, nursing schools can help shape and develop management and leadership skills in students for future leadership and management roles. ${ }^{23}$ Findings of Kilgore et al. and Sharpnack et al. showed that simulation experiences may enhance nursing students' management skills such as prioritising and managing staff workloads, delegating, working with inter-professional health teams and making critical decisions. ${ }^{24,25}$ While there is mounting evidence concerning the use and usefulness of simulation in teaching management and leadership courses, at present, this evidence does not present a wider viewpoint on this essential topic. This integrative review aimed to determine the outcomes of using simulation in pre-licensure nursing management and leadership courses.

\section{Methods}

An integrative review approach guided by the framework devised by Whittemore and Knafl informed this study. ${ }^{26}$ This approach was deemed suitable as it allowed the combination of findings of studies with both experimental or non-experimental designs to provide a broader perspective on the topic.

To locate relevant articles published between 2008 and 2018, an electronic search of databases was conducted in January 2019. MEDLINE, Psych INFO,
CINAHL and SCOPUS were used to locate and search for original articles using the following search and Medical Subject Headings terms: 'management', 'leadership', 'simulation', 'nursing', 'education' and 'student.' Furthermore, a manual search of relevant literature was carried out based on the list of references in the articles included [Figure 1].

The following inclusion criteria were considered in the search and retrieval of the articles: (1) original articles examining the use of simulation-based activities in teaching management and leadership skills in prelicensure nursing programmes; (2) articles published in refereed journals within the last 10 years; and (3) articles written in the English language.

A total of 198 articles were retrieved during the initial search of the databases. After removing duplicates, 136 articles were retained. Titles and abstracts were further screened and compared using the inclusion criteria, with 45 articles being considered for full-text screening. Finally, 10 studies were considered appropriate for the review after a fulltext reading of the articles; the remaining 35 articles were excluded because simulation procedures were either not clearly described, the processes were not purely simulation-based and contained studies or the participants were combined with others from a different healthcare profession [Figure 1].

The quality, rigor, credibility and trustworthiness of the research methods used in the articles included in the review were examined using the Mixed Methods Appraisal Tool by two independent reviewers. ${ }^{27}$ This appraisal tool was designed to assess the quality of studies (e.g. quantitative, qualitative and mixedmethod studies). Based on the criteria set, a score was assigned that ranged from $25 \%$ to $100 \%$. In this review, no articles were excluded based on the quality score due to a lack of studies that pertained to simulation as utilised in nursing leadership and management

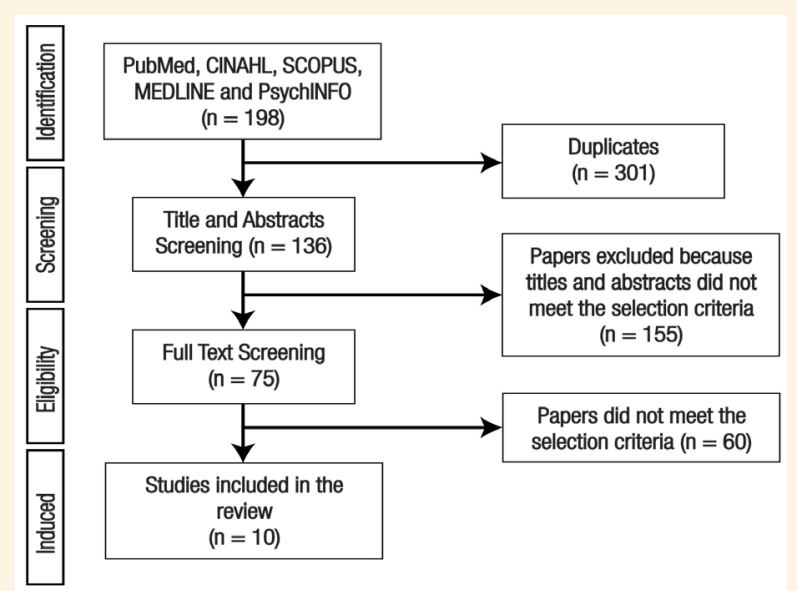

Figure 1: Flowchart showing the selection process used to identify articles included. 
courses; instead, the tool was used to appraise the methodological quality of the articles reviewed.

Using a common template, essential data were extracted from the articles by two independent researchers, which included the authors, research design, subjects/simulation duration/debriefing duration, type of simulation/measures and key findings [Table 1]. 7,24,25,28-34 Data were synthesised following the content analysis guided by the constant comparison approach. ${ }^{35}$ Specifically, similar categories and subcategories were clustered by comparing each definition and the prevalence of certain themes was determined. Encompassing themes were discussed and further analysed by the researchers to arrive at common and most suitable theme names. This approach in data synthesis is compatible with an integrative review that includes studies with varied research methodologies to analyse and synthesise. ${ }^{27}$

\section{Results}

\section{STUDY CHARACTERISTICS}

Based on the inclusion criteria, 10 articles published in the last 10 years were included in this review. The vast majority of the articles reviewed ( $\mathrm{n}=7,70 \%$ ) originated and were conducted in the USA and the remaining articles were from other countries such as Ireland, Australia and Canada. Six studies (60\%) utilised a descriptive research design, two adopted a one-group pre- and post-test design, one employed a mixed-method design and the other used a two-group post-test design. $7,24,25,28-34$ The sample sizes ranged from 24 to 155 .

In the quantitative studies, some scales were utilised to measure outcomes of simulation such as the Student Satisfaction and Self-confidence in Learning Scale and the Clinical Learning Environments Comparison Survey (CLECS). ${ }^{36,37}$ In four studies, a researcher-designed survey tool was used, while in one study (the Nursing Leadership Content Mastery Assessment) a standardised computer-based assessment tool, developed by Assessment Technologies Institute, was used. ${ }^{38}$ Duration of simulation ranged from 20 minutes to 1.5 hours, while the debriefing duration ranged from 20 minutes to 1 hour. Concerning the quality score of the articles reviewed, the scores ranged from $80 \%$ to $90 \%$ out of a possible total score of $100 \%$.

\section{SIMULATION MODALITY AND SCENARIO}

In this review, patient/clinical case scenarios employing high-fidelity mannequins, medium-fidelity simulators, low-fidelity simulators and used standardised patients during simulation. Simulation scenarios involved handling and caring for patients with various medical and surgical conditions including obstetric and gynaecologic, psychiatric, paediatric and gerontology patients. In articles with a control group, low- or mediumfidelity simulations or traditional clinical placements or demonstrations were used.

\section{KEY FINDINGS}

Four themes were identified from the content analysis: acquisition of skills or understanding of delegation, enhanced teamwork or collaboration capacities, improved decision-making and problem-solving skills and increased communication skills [Figure 2].

\section{ACQUISITION OF SKILLS OR UNDERSTANDING OF DELEGATION}

Five studies determined the impact of simulation-based learning on nursing students' acquisition of delegation skills and/or understanding of delegation. ${ }^{24,25,29,32,34}$ Hourican et al. assessed the usefulness of simulation in promoting management skills in senior nursing students using high-fidelity mannequins and standardised patients. $^{34}$ Overall, nursing students reported higher levels of awareness and understanding in the following competencies: prioritising and managing staff workloads,effective delegation and maintaining patient safety. In Australia, students who were exposed to high-fidelity simulation expressed that the simulation experiences improved their skills in prioritising, delegation and time management..$^{32}$ Three studies in the USA yielded similar outcomes..$^{24,25,29}$ Nursing students who experienced simulation scenarios using medium-fidelity simulators and standardised patients obtained higher scores on delegation subscales when compared to those in nonsimulation groups. ${ }^{25}$ Similarly, an increased knowledge ( $n=66,68 \%)$ and higher confidence levels ( $n=53,55 \%)$ on delegating patient care and prioritising were seen in senior nursing students after simulation exposure. ${ }^{29}$ In a descriptive qualitative study by Kilgore et al., three essential themes emerged from the nursing student simulation evaluations: the nursing students felt that the experience was convincing, it fostered their ability to delegate and reinforced leadership and management concepts. $^{24}$

\section{ENHANCED TEAMWORK OR COLLABORATION CAPACITIES}

Another prominent theme that emerged from the content analysis was 'teamwork or collaboration' which was found in five studies. ${ }^{24,25,29,32,34}$ In an Irish study, senior nursing students who were exposed to simulation scenarios using medium-fidelity simulators obtained higher scores in the following areas: providing support to colleagues, teamwork and interaction with the multidisciplinary team. ${ }^{34}$ In one study that compared 
Table 1: Summary of studies evaluating the use of simulation in teaching nursing leadership and management courses ${ }^{7,24,25,28-34}$

\begin{tabular}{|c|c|c|c|c|}
\hline $\begin{array}{l}\text { Author } \\
\text { (year of } \\
\text { publication)/ } \\
\text { country }\end{array}$ & $\begin{array}{l}\text { Research } \\
\text { design }\end{array}$ & $\begin{array}{l}\text { Subjects, } \\
\text { simulation } \\
\text { duration and } \\
\text { debriefing } \\
\text { duration }\end{array}$ & $\begin{array}{c}\text { Type of simulation/ } \\
\text { measures }\end{array}$ & Key findings \\
\hline $\begin{array}{l}\text { Brown and } \\
\text { Rode }^{33}(2018) / \\
\text { USA }\end{array}$ & $\begin{array}{l}\text { - Mixed } \\
\text { methods/ } \\
\text { One-group } \\
\text { pre- and } \\
\text { post-test }\end{array}$ & $\begin{array}{l}-79 \text { sophomores, } \\
69 \text { juniors, } 62 \\
\text { seniors } \\
-30 \text { minutes of } \\
\text { simulation } \\
-20 \text { minutes of } \\
\text { debriefing }\end{array}$ & $\begin{array}{l}\text { - High-fidelity } \\
\text { simulators } \\
\text { - Scale: SSLC }\end{array}$ & $\begin{array}{l}\text { - Students reported high levels of satisfaction } \\
\text { with their high-fidelity simulators } \\
\text { experiences. } \\
\text { - Sophomores and juniors felt more relaxed } \\
\text { with a peer facilitator versus a faculty } \\
\text { member. } \\
\text { - Seniors reported simulation provided them } \\
\text { opportunity to develop leadership skills, } \\
\text { empower others and translate management } \\
\text { and leadership concept to practice. }\end{array}$ \\
\hline $\begin{array}{l}\text { Hourican et } \\
\text { al. }^{34}(2008) / \\
\text { Ireland }\end{array}$ & $\begin{array}{l}\text { - Mixed } \\
\text { methods }\end{array}$ & $\begin{array}{l}\text { - } 68 \text { students } \\
\text { - Simulation was } \\
\text { within four hours } \\
\text { of independent } \\
\text { learning }\end{array}$ & $\begin{array}{l}\text { - Medium-fidelity } \\
\text { mannequins, } \\
\text { standardised patients } \\
\text { - Scale: Researcher- } \\
\text { designed evaluation } \\
\text { criteria for the } \\
\text { simulation experience }\end{array}$ & $\begin{array}{l}\text { - Majority of students responded positively to } \\
\text { simulation as it increased their confidence in } \\
\text { their own ability. } \\
\text { - Students stated they felt that their } \\
\text { 'confidence increased' when they achieved } \\
\text { what they had to do. } \\
\text { - A majority of students stated that they } \\
\text { would participate again in the simulation. } \\
\text { - A majority of students indicated that the } \\
\text { simulation exercise reflected the reality of the } \\
\text { clinical environment. } \\
\text { - Student's ratings of their own level } \\
\text { of knowledge were increased after the } \\
\text { exercise in the following areas: supporting } \\
\text { colleagues and working as a team member, } \\
\text { managing resources efficiently and effectively, } \\
\text { maintaining patient safety, dealing with } \\
\text { unusual or unexpected events (problem- } \\
\text { solving), prioritising and managing an } \\
\text { allocated workload, recognising changes in } \\
\text { physical, emotional, social or psychological } \\
\text { health status and taking appropriate } \\
\text { action, recognising professional and ethical } \\
\text { dilemmas, maintaining patient confidentiality, } \\
\text { adhering to local and national policies, } \\
\text { procedures and guidelines, gathering } \\
\text { and recording relevant information and } \\
\text { communicating with colleagues including } \\
\text { members of the multidisciplinary team. }\end{array}$ \\
\hline $\begin{array}{l}\text { Gore et al. }{ }^{7} \\
(2015) / \text { USA }\end{array}$ & - Descriptive & $\begin{array}{l}\text { - } 155 \text { students } \\
\text { - } 30 \text { to } 40 \text { minutes } \\
\text { of simulation } \\
\text { - } 20 \text { to } 25 \text { minutes } \\
\text { ofdebriefing }\end{array}$ & $\begin{array}{l}\text { - Low-fidelity } \\
\text { mannequins and } \\
\text { a medium-level } \\
\text { environmental fidelity } \\
\text { - Scale: CLECS }\end{array}$ & $\begin{array}{l}\text { - Students rated communication high in the } \\
\text { traditional clinical environment. } \\
\text { - Teaching-learning needs were rated high in } \\
\text { the simulated clinical environment. } \\
\text { - Nursing leadership was rated high in both } \\
\text { groups. }\end{array}$ \\
\hline
\end{tabular}


Table 1 (cont'd): Summary of studies evaluating the use of simulation in teaching nursing leadership and management courses $7,24,25,28-34$

\begin{tabular}{|c|c|c|c|c|}
\hline $\begin{array}{l}\text { Author } \\
\text { (year of } \\
\text { publication)/ } \\
\text { country }\end{array}$ & $\begin{array}{l}\text { Research } \\
\text { design }\end{array}$ & $\begin{array}{l}\text { Subjects, } \\
\text { simulation } \\
\text { duration and } \\
\text { debriefing } \\
\text { duration }\end{array}$ & $\begin{array}{c}\text { Type of simulation/ } \\
\text { measures }\end{array}$ & Key findings \\
\hline $\begin{array}{l}\text { Kilgore et al. }{ }^{24} \\
\text { (2013)/USA }\end{array}$ & - Descriptive & $\begin{array}{l}\text { - } 24 \text { students } \\
\text { - Duration of } 45 \\
\text { minutes }\end{array}$ & $\begin{array}{l}\text { - High-fidelity } \\
\text { simulators using } \\
\text { 3G Simman } \\
\text { mannequins, one child } \\
\text { mannequin and one } \\
\text { live standardised client }\end{array}$ & $\begin{array}{l}\text { - Students had improved their ability to } \\
\text { delegate, helped to identify their deficits, } \\
\text { improved their ability to work in a team } \\
\text { and reinforced leadership and management } \\
\text { concepts. }\end{array}$ \\
\hline $\begin{array}{l}\text { Pollard and } \\
\text { Wild }^{30}(2014) / \\
\text { Canada }\end{array}$ & - Descriptive & $\begin{array}{l}\text { - Students in } \\
\text { leadership in } \\
\text { nursing course } \\
\text { - Within the } \\
\text { allotted nine hours }\end{array}$ & $\begin{array}{l}\text { - Low-fidelity } \\
\text { leadership and } \\
\text { followership } \\
\text { simulation exercises }\end{array}$ & $\begin{array}{l}\text { - Students could identify how leadership and } \\
\text { followership skills would be used within their } \\
\text { next clinical experience and the importance } \\
\text { of these attributes as being essential to their } \\
\text { future career as a nurse. } \\
\text { - Students also reported that participating in } \\
\text { the activities was realistic and they felt like } \\
\text { the decisional complexities experienced in the } \\
\text { class were likely the ones they would also need } \\
\text { to deal with in their future practice. } \\
\text { - As observed by the faculty concerned, the } \\
\text { students were able to come prepared, have } \\
\text { improved communication and professional } \\
\text { identity within their teams and developed } \\
\text { collaborative team communication approaches } \\
\text { within a social awareness of individual, team } \\
\text { and organisation needs, and, thus, ended up } \\
\text { being better prepared for interprofessional } \\
\text { healthcare teams. }\end{array}$ \\
\hline $\begin{array}{l}\text { Thomas et al. }{ }^{31} \\
\text { (2011)/USA }\end{array}$ & $\begin{array}{l}\text { - Descriptive } \\
\text { design }\end{array}$ & - 132 students & $\begin{array}{l}\text { - High-fidelity } \\
\text { simulators, } \\
\text { standardised patients } \\
\text { - Scale: Researcher- } \\
\text { designed scale to } \\
\text { measure simulation } \\
\text { and learning } \\
\text { experiences }\end{array}$ & $\begin{array}{l}\text { - Students perceived that they can apply } \\
\text { decision-making skills for several situations } \\
\text { not otherwise encountered. } \\
\text { - The majority of students reported enhanced } \\
\text { ability to apply decision-making, problem- } \\
\text { solving and critical thinking. } \\
\text { - A majority of the students reported } \\
\text { preparedness to assume charge nurse position. } \\
\text { - A majority of the students reported higher } \\
\text { levels of understanding on the following } \\
\text { charge nurse roles: communication, } \\
\text { collaboration, cooperation, time management, } \\
\text { decision-making, critical thinking, problem- } \\
\text { solving and delegation. }\end{array}$ \\
\hline $\begin{array}{l}\text { Warland } \\
\text { (2011)/Australia }\end{array}$ & $\begin{array}{l}\text { - One-group } \\
\text { pre- and post- } \\
\text { test design }\end{array}$ & $\begin{array}{l}\text { - } 115 \text { nursing } \\
\text { students } \\
\text { - } 30 \text { to } 45 \text { minutes } \\
\text { of simulation } \\
\text { - } 30-40 \text { minutes of } \\
\text { debriefing }\end{array}$ & $\begin{array}{l}\text { - High-fidelity } \\
\text { simulators } \\
\text { - Scale: Researcher- } \\
\text { designed scale to } \\
\text { measure simulation } \\
\text { and learning } \\
\text { experiences }\end{array}$ & $\begin{array}{l}\text { - Most students felt the simulations } \\
\text { increased their understanding of systems and } \\
\text { organisation of nursing care. } \\
\text { - Students reported gaining skills and } \\
\text { understanding on the following: time } \\
\text { management, teamwork and prioritising } \\
\text { strategies. } \\
\text { - } 20 \text { students (43\%) reported that simulation } \\
\text { helped them with organisational skills on their } \\
\text { clinical placement. } \\
\text { - } 36 \% \text { reported that simulation helped them } \\
\text { with their proper skills. }\end{array}$ \\
\hline
\end{tabular}

SSLC = Student Satisfaction and Self-confidence in Learning Scale; CLECS = Clinical Learning Environments Comparison Survey.

nursing students who had attended simulation activities, a significantly lower score in the 'collaborate' subscale of the Nursing Leadership Content Mastery Assessment was observed in students who had not attended simulation. ${ }^{25}$ A similar finding was observed in an Australian study which identified improvements in the following competencies: time management, teamwork and strategies for prioritization. ${ }^{32}$ 


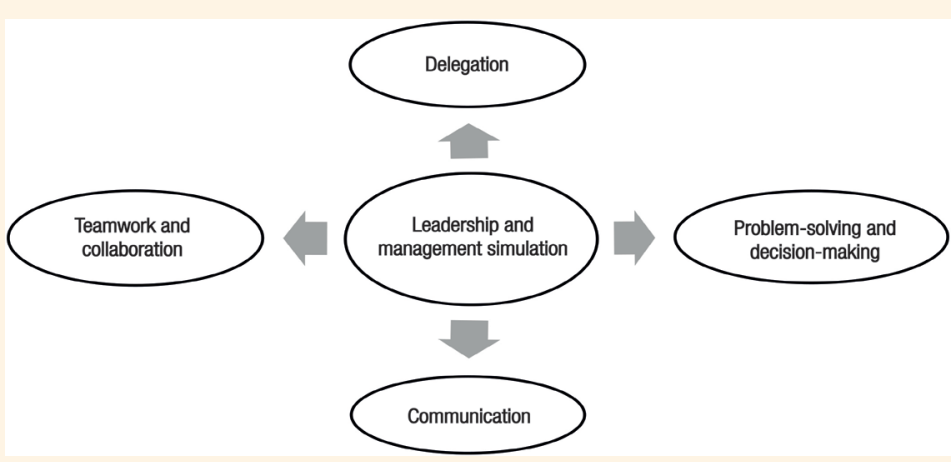

Figure 2: Diagram of themes generated during the review.

Results of nursing students' simulation evaluation, using a researcher-designed simulation-based learning exercise evaluation, showed higher levels of confidence in working as a team with nursing students who had attended a 20-minute simulation activity. ${ }^{29}$ An important theme that emerged in the qualitative analysis by Kilgore et al. was an enhancement in nursing students' ability to work within the healthcare team as well as reinforcement of leadership and management concepts learned in the classroom. ${ }^{24}$

\section{IMPROVED DECISION-MAKING AND PROBLEM-SOLVING SKILLS}

Enhanced decision-making and problem-solving skills were identified as an essential outcome of the simulation. ${ }^{29,31}$ Che'Reed et al. implemented a leadership management simulation in the USA in a group of students participating in a nurse leadership and management course. $^{28}$ After participation in a simulation scenario that involved a patient with severe incisional pain, the nursing students obtained a higher awareness of the following areas of nursing management: responding to emergencies, planning for addressing potential complications and making quick clinical decisions. Similar findings were observed in a descriptive study by Thomas et al. wherein out of 132 senior-level nursing students who had attended the simulation experiences, 95\% expressed greater confidence in making ward/unit decisions, solving problems and critical thinking. ${ }^{31}$

\section{INCREASED COMMUNICATION SKILLS}

The effects of simulation-based activities on students' skills in communicating effectively with patients and the healthcare team were evaluated in three studies. ${ }^{731,34}$ In a leadership simulation study by Hourican et al. using medium- and high-fidelity simulators and standardised patients, nursing students (after simulation) reported an increase in competence in communicating with colleagues and the other members of the multidisciplinary healthcare team, along with other competencies such as effectively working with the team, recognising professional and ethical issues, managing staff workloads and dealing with unforeseen events in the ward/unit. ${ }^{34}$ In a descriptive study by Thomas et al., there was a higher proportion of nursing students who attended a chargenurse simulation scenario and expressed an increased knowledge of the charge-nurse role in collaborating and effectively communicating with the staff nurse subordinates and other healthcare team members. ${ }^{31}$ In the USA, Gore et al. compared the efficacy of simulated and traditional clinical environments on leadership learning in nursing students. ${ }^{7}$ After 30 to 40 minutes of simulation using low-fidelity mannequins, nursing students evaluated their simulation experience using the CLECS. Although the scores in the nursing leadership skills were equally high among the two groups, the communication subscales were significantly higher among nursing students who had attended the traditional learning placement when compared to nursing students in the simulation group. ${ }^{7}$

\section{Discussion}

This integrative review synthesised and appraised available literature examining the influence of simulation activities in fostering management and leadership skills among student nurses. A total of 10 studies, primarily with quantitative research designs, informed the findings of this review. While the researchers found some evidence that supported simulation as a modality in teaching management and leadership courses in nursing students, caution should be exercised when making inferences due to the scarcity of high-quality evidence.

Simulation studies demonstrated a positive influence of simulation-based activities for nursing students' understanding or knowledge of and awareness of delegation. Delegation is a key function of a professional nurse and is defined as "the transfer of 
responsibility for the performance of an activity from one individual to another while retaining accountability for the outcome".39 Ineffective delegation often leads to negative patient outcomes. ${ }^{40}$ While delegation is considered an important nursing function, this skill often remains underdeveloped in newly graduated nurses and pre-licensure education is often accused of not adequately preparing nursing students to perform this essential role. ${ }^{41}$ In a study in the UK, new nurses reported limited clinical opportunities to translate the concept of delegation into practice and to develop competencies to effectively supervise, manage and organise care during their pre-licensure nursing education. ${ }^{40}$ Nevertheless, nursing faculty can strengthen delegation skills and facilitate the formation of delegation skills among nursing students; the simulation laboratory can be a good avenue to foster this skill.

Collaboration and communication emerged as important outcomes of simulation. The Inter-professional Education Collaborative recognised teamwork or collaboration and communication as an important component of a patient-centred care practice. ${ }^{42}$ Available studies have identified the relevance of collaborative health practice, which is characterised by constant interaction, communication, collaboration and engagement among interprofessional healthcare workers along with patients and their families in attaining quality healthcare and positive patient outcomes, ultimately reducing costs of healthcare and improving organisational productivity. ${ }^{43,44}$ Despite higher emphasis on the importance of effective communication and collaboration during the undergraduate programme, many new nurses expressed challenges in effectively communicating, collaborating and working with other healthcare teams, patients and their relatives. ${ }^{45,46}$ This review's finding supports international studies highlighting the essential role of simulation in enhancing collaboration, communication and teamwork among healthcare workers from different professions. ${ }^{25,47}$

Furthermore, simulation showed a positive impact on nursing students' abilities to solve problems and make critical decisions regarding patient care and ward/ unit management. Problem-solving and decisionmaking are considered key processes in nursing. In particular, clinical decision-making among nurses is critically important when selecting interventions and treatments for patients and in addressing their needs. ${ }^{48}$ According to Standing, decision-making skills, which is a central aspect of quality nursing care, can be developed during the undergraduate period to equip future nurses with the realities and challenges that they will encounter when they assume the professional nursing role. ${ }^{49}$ However, many new nurses reported to be lacking in these essential skills and complained that their undergraduate education had not placed a high enough emphasis on this area of development. ${ }^{46}$

Whereas all simulation studies showed potential in enhancing a variety of leadership and management competencies, cautionshouldbeexercisedwhen making inferences due to the presence of certain methodological issues. For instance, most studies reviewed used either a descriptive design or a one-group pre- and post-test design. While many nursing and healthcare scholars have utilised pre- and post-test designs for research, unlike randomised control trials (RCTs), confounding variables that may affect the intervention outcomes are not or are poorly controlled. Conversely, findings of RCTs can generate high levels of evidence and are therefore useful as they can be used to guide policy implementers, healthcare managers and nurse leaders. Thus, future studies on simulation should be conducted utilising a more robust research design.

Another key observation was the lack of standardised scales in the included studies specific to measuring leadership and management skills in nursing students. Four studies utilised a researcherdesigned survey tool and in the remaining studies outcomes of simulation were evaluated using the SSCL, the Nursing Leadership Content Mastery Assessment and the CLECS. Although these tools are validated, they are not specific to measuring leadership and management competencies in nursing students. As opined by Foronda et al., evaluation of simulation efficacy using established instruments is critical. ${ }^{50}$ This highlights the need for a simulation tool specific to measuring leadership and management skills in students. It is worth noting that leadership and management competencies and study subjects were evaluated using self-report tools rather than a direct measure of participants' competencies. However, Baxter and Lederman suggested that self-reporting may not be an accurate measure of actual ability or performance; ${ }^{51}$ thus, additional objective evaluation measures should be used to determine these essential competencies.

Power analysis or sample calculation is vital as sample size affects the transferability and generalisability of research findings. In this review, most of the studies included had inadequate sample sizes and none utilised a power analysis to identify the number of samples to be included to yield significant findings. In addition, the duration of the simulation-based activities varied significantly, ranging from 20 minutes to 1.5 hours, while the duration of debriefing ranged from 20 minutes to 1 hour. This certainly poses an inquiry as to how long a simulation activity should 
be delivered to nursing students to cause significant change in their knowledge and skills. Furthermore, simulation trainings of the simulation facilitators were rarely described. These factors should be considered in future simulation research as they may affect the outcomes of simulation and, thus, the generalisability of the findings.

Moreover, the studies reviewed originated mainly in the USA, Ireland, Australia and Canada. With the influx of foreign nurses from Asian countries (China, India and the Philippines) to Western countries (Canada, the UK and the USA), this finding poses a question with regard to the preparedness of these foreign nurses to assume nursing leadership roles..$^{52}$ It emphasises the importance of the integration of leadership simulation in the nursing curricula, especially in the abovementioned non-Western countries, to ensure that the nursing graduates from these curricula are prepared for future leadership and management roles and possess managerial and leadership competencies.

Despite the promising outcomes of leadership and management simulations, it is apparent that further efforts are needed when designing simulation activities that incorporate essential leadership and management competencies as defined by the AONE and are vital in the overall productivity and effectiveness of any healthcare organisation.

\section{IMPLICATIONS FOR NURSING EDUCATION}

This review's findings highlight the value of simulation as a powerful tool in teaching leadership and management courses as well as the potential of enhancing certain leadership and management skills among nursing students. Amidst the increasing challenges being confronted in this regard by faculty, the incorporation of simulation into nursing management and leadership courses has the potential to enhance students' skills pertaining to delegation, problem-solving and decision-making, communication and teamwork. Incorporation of simulation-based activities in nursing management, leadership courses and other nursing courses may be useful in the translation of theoretical knowledge into nursing practice. In doing so, nursing schools should ensure that nursing faculty have leadership expertise and are able to provide relevant leadership and management simulation courses or trainings to better support the learning needs of the pre-licensure nursing students. In addition, simulation resources should be provided to create a more realistic scenario necessary to deliver the intended learning outcomes.

\section{Conclusion}

This review provided up-to-date knowledge related to the current state of simulation-based activities in leadership and management courses in pre-licensure nursing programmes. The findings of this review support previous simulation studies underlining the significance of this teaching-learning method in enhancing a variety of nursing student outcomes.

\section{CONFLICT OF INTEREST}

The authors declare no conflicts of interest.

\section{FUNDING}

No funding was received for this study.

\section{References}

1. Institute of Medicine. The Future of Nursing: Leading Change, Advancing Health. Washington, DC: The National Academies Press, 2011.

2. American Association of Colleges of Nursing. The Essentials of Baccalaureate Education for Professional Nursing Practice. From: https://www.aacnnursing.org/portals/42/publications/ baccessentials08.pdf Accessed: Sep 2020.

3. American Organization of Nurse Managers. The role and functions of the hospital nurse manager. Nurs Manage 1992; 23:36-8.

4. Yuan HB, Williams BA, Fang JB. The contribution of highfidelity simulation to nursing students' confidence and competence: A systematic review. Int Nurs Rev 2012; 59:26-33. https:// doi.org/10.1111/j.1466-7657.2011.00964.x.

5. Curtis EA, de Vries J, Sheerin FK. Developing leadership in nursing: Exploring core factors. Br J Nurs 2011; 20:306-9. https://doi.org/10.12968/bjon.2011.20.5.306.

6. Chunta K, Edwards T. Multiple-patient simulation to transition students to clinical practice. Clin Simul Nurs 2013; 9:e491-6. https://doi.org/10.1016/j.ecns.2013.04.015

7. Gore TN, Johnson TL, Wang CH. Teaching nursing leadership: Comparison of simulation versus traditional inpatient clinical. Int J Nurs Educ Scholarsh 2015; 12:55-63. https://doi.org/1 0.1515/ijnes-2014-0054.

8. Schubert CR. Effect of simulation on nursing knowledge and critical thinking in failure to rescue events. J Contin Educ Nurs 2012; 43:467-71. https://doi.org/10.3928/00220124-20120904-27.

9. Bowling AM, Underwood PW. Effect of simulation on knowledge, self-confidence, and skill performance in the USA: A quasi-experimental study. Nurs Health Sci 2016; 18:292-8. https://doi.org/10.1111/nhs.12267.

10. Stroup C. Simulation usage in nursing fundamentals: Integrative literature review. Clin Simul Nurs 2014; 10:e155-64. https:// doi.org/10.1016/j.ecns.2013.10.004.

11. Germain M, O'Leary-Kelley C, Goyal D, Anand S. Can clinical simulation increase confidence levels in performing postpartum care in a diverse group of baccalaureate nursing students? Nurs Educ Perspect 2018; 39:94-5. https://doi.org/10.1097/01.NEP. 0000000000000233.

12. Wright RR, Tinnon EA, Newton RH. Evaluation of vSim for| nursing in an adult health nursing course: A multisite pilot study. Comput Inform Nurs 2018; 36:84-9. https://doi.org/10.1097/ CIN.0000000000000388 
13. Vandyk AD, Lalonde M, Merali S, Wright E, Bajnok I, Davies B. The use of psychiatry-focused simulation in undergraduate nursing education: A systematic search and review. Int J Ment Health Nurs 2018; 27:514-35. https://doi.org/10.1111/ inm.12419.

14. Lubbers J, Rossman C. Satisfaction and self-confidence with nursing clinical simulation: Novice learners, medium-fidelity, and community settings. Nurse Educ Today 2017; 48:140-4. https://doi.org/10.1016/j.nedt.2016.10.010.

15. Brien LA, Charette M, Goudreau J. Nursing students' perceptions of the contribution of high-fidelity simulation and clinical placement in a critical care course. Clin Simul Nurs 2017; 13:436-41. https://doi.org/10.1016/j.ecns.2017.05.005.

16. Centrella-Nigro AM, Blackwell B, Coughlin A, Voorhees KA. The effect of human patient simulators on knowledge and selfcompetence in graduating prelicensure nursing students. Nurs Educ Perspect 2016; 37:337-9. https://doi.org/10.1097/01. NEP.0000000000000072.

17. Adib-Hajbaghery M, Sharifi N. Effect of simulation training on the development of nurses and nursing students' critical thinking: A systematic literature review. Nurse Educ Today 2017; 50:17-24. https://doi.org/10.1016/j.nedt.2016.12.011.

18. Gates MG, Parr MB, Hughen JE. Enhancing nursing knowledge using high-fidelity simulation. J Nurs Educ 2012; 51:9-15. https://doi.org/10.3928/01484834-20111116-01.

19. Forneris SG, Neal DO, Tiffany J, Kuehn MB, Meyer HM, Blazovich LM, et al. Enhancing clinical reasoning through simulation debriefing: A multisite study. Nurs Educ Perspect 2015; 36:304-10. https://doi.org/10.5480/15-1672.

20. Foronda C, Gattamorta K, Snowden K, Bauman EB. Use of virtual clinical simulation to improve communication skills of baccalaureate nursing students: A pilot study. Nurse Educ Today 2014; 34:e53-7. https://doi.org/10.1016/j.nedt.2013.10.007.

21. Fawaz MA, Hamdan-Mansour AM. Impact of high-fidelity simulation on the development of clinical judgment and motivation among Lebanese nursing students. Nurse Educ Today 2016; 46:36-42. https://doi.org/10.1016/j.nedt.2016.08.026.

22. Hayden JK, Smiley RA, Alexander M, Kardong-Edgren S, Jeffries PR. The NCSBN national simulation study: A longitudinal, randomized, controlled study replacing clinical hours with simulation in prelicensure nursing education. J Nurs Reg 2014; 5:C1-S64. https://doi.org/10.1016/S2155-8256(15)30062-4.

23. Smith SB. Integrating simulation in a BSN leadership and management course. J Nurs Educ Pract 2013; 3:121-5. https:// doi.org/10.5430/jnep.v3n11p121.

24. Kilgore RV, Goodwin ME, Harding RA. Adding context to a simulation module for leadership and management baccalaureate nursing students. J Nurs Educ Pract 2013; 3:148-55. https://doi.org/10.5430/jnep.v3n9p148.

25. Sharpnack PA, Goliat L, Rogers K. Using standardized patients to teach leadership competencies. Clin Simul Nurs 2013; 9:e95-102. https://doi.org/10.1016/j.ecns.2011.10.001.

26. Whittemore R, Knafl K. The integrative review: Updated methodology. J Adv Nurs 2005; 52:546-53. https://doi.org/10.1111/j.13 65-2648.2005.03621.x.

27. Pace R, Pluye P, Bartlett G, Macaulay AC, Salsberg J, Jagosh J, et al. Testing the reliability and efficiency of the pilot Mixed Methods Appraisal Tool (MMAT) for systematic mixed studies review. Int J Nurs Stud 2012; 49:47-53. https://doi.org/10.10 16/j.ijnurstu.2011.07.002.

28. Che'Reed C, Lancaster RR, Musser DB. Nursing leadership and management simulation creating complexity. Clin Simul Nurs 2009; 5:e17-21.

29. Kaplan B, Ura D. Use of multiple patient simulators to enhance prioritizing and delegating skills for senior nursing students. J Nurs Educ 2010; 49:371-7. https://doi.org/10.3928/0148483420100331-07.
30. Pollard CL, Wild C. Nursing leadership competencies: Low-fidelity simulation as a teaching strategy. Nurs Educ Pract 2014; 14:620-626. https://doi.org/10.1016/j.nepr.2014.06.006.

31. Thomas C, Hodson-Carlton K, Ryan M. Preparing nursing students in a leadership/management course for the workplace through simulations. Clin Simul Nurs 2011; 7:e99-104. https://doi. org/10.1016/j.ecns.2010.06.005.

32. Warland J. Using simulation to promote nursing students' learning of work organization and people management skills: A casestudy. Nurse Educ Pract 2011; 11:186-91. https://doi.org/10.10 16/j.nepr.2010.08.007.

33. Brown KM, Rode JL. Leadership development through peerfacilitated simulation in nursing education. J Nurs Educ 2018; 57:53-7. https://doi.org/10.3928/01484834-20180102-11.

34. Hourican S, McGrath M, Lyng C, McMahon C, Lehwaldt D. Effectiveness of simulation on promoting student nurses management skills. Int J Clin Skills 2008; 2:20-25.

35. Lincoln YS, Guba EG. Naturalistic Inquiry. Beverly Hills, CA: Sage Publications, 1985.

36. Jeffries PR, Rizzolo MA. Designing and Implementing Models for the Innovative Use of Using Simulation to Teach Nursing Care of Ill Adults and Children: A National, Multi-Site, MultiMethod Study. New York, NY: National League for Nursing, 2006.

37. Leighton K. Development of the clinical learning environment comparison survey. Clin Simul Nurs 2015; 11:44-51. https:// doi.org/10.1016/j.ecns.2014.11.002.

38. Assessment Technologies Institute, LLC. Evaluating the Predictive Power of ATI's RN Comprehensive Predictor 2010. 2013. From: https://www.atitesting.com/docs/default-source/research/ research-brief---rn_cptonclex.pdf?sfvrsn=c7e006e9_0 Accessed: Sep 2020.

39. Weberg D, Mangold K, Porter-O'Grady T, Malloch K. Leadership in Nursing Practice: Changing the Landscape of Health Care: Changing the Landscape of Health Care, 3rd ed. Burlington, USA: Jones \& Bartlett Learning, 2018.

40. Magnusson C, Allan H, Horton K, Johnson M, Evans K, Ball E. An analysis of delegation styles among newly qualified nurses. Nurs Stand 2017; 31:46-53. https://doi.org/10.7748/ns.2017. e9780.

41. Hasson F, McKenna HP, Keeney S. Delegating and supervising unregistered professionals: The student nurse experience. Nurse Educ Today 2013; 33:229-35. https://doi.org/10.1016/j. nedt.2012.02.008.

42. Interprofessional Education Collaborative (IPEC). Team-Based Competencies: Building a Shared Foundation for Education and Clinical Practice. 2011. From: https://www.gih.org/files/ IPE $\% 20$ conference $\% 20$ proceedings\%20Report_5211.pdf Accessed: Sep 2020.

43. Reeves S, Fletcher S, Barr H, Birch I, Boet, S, Davies N, et al. A BEME systematic review of the effects of interprofessional education: BEME Guide No. 39. Med Teach 2016; 38:656-68. https://doi.org/10.3109/0142159X.2016.1173663.

44. Reeves S, Perrier L, Goldman J, Freeth D, Zwarenstein M. Interprofessional education: Effects on professional practice and healthcare outcomes (update). Cochrane Database Syst Rev 2013; 3:CD002213. https://doi.org/10.1002/14651858.CD002213.pub3.

45. Parker V, Giles M, Lantry G, McMillan M. New graduate nurses' experiences in their first year of practice. Nurse Educ Today 2014; 34:150-56. https://doi.org/10.1016/j.nedt.2012.07.003.

46. Wong SWJ, Che WSW, Cheng MTC, Cheung CK, Cheung TYJ, Lee KY, et al. Challenges of fresh nursing graduates during their transition period. J Nurs Educ Pract 2018; 8:30-7. https://doi. org/10.5430/jnep.v8n6p30.

47. Labrague LJ, McEnroe-Petitte DM, Fronda DC, Obeidat AA. Interprofessional simulation in undergraduate nursing program: An integrative review. Nurse Educ Today 2018; 67:46-55. https://doi.org/10.1016/j.nedt.2018.05.001. 
48. Tiffen J, Corbridge SJ, Slimmer L. Enhancing clinical decision making: Development of a contiguous definition and conceptual framework. J Prof Nurs 2014; 30:399-405. https://doi.org/10.10 16/j.profnurs.2014.01.006.

49. Standing M. Clinical Judgment and Decision Making for Nursing Student. Devon: Learning Matters Ltd., 2011.

50. Foronda C, Liu S, Bauman EB. Evaluation of simulation in undergraduate nurse education: An integrative review. Clin Simul Nurs 2013; 9:e409-16. https://doi.org/10.1016/j.ecns.2012.11.003.
51. Baxter JA, Lederman NG. Assessment and measurement of pedagogical content knowledge. In: Gess-Newsome J, Lederman NG, Eds. Examining Pedagogical Content Knowledge. Dordrecht: Springer, 1999. pp. 147-161.

52. Pung LX, Goh YS. Challenges faced by international nurses when migrating: An integrative literature review. Int Nurs Rev 2017; 64:146-65. https://doi.org/ 10.1111/inr.12306. 